\title{
Combinatorial assessments of brain tissue metabolomics and histopathology in rodent models of human immunodeficiency virus infection
}

\author{
Adrian A. Epstein - Prabagaran Narayanasamy • Prasanta K. Dash • \\ Robin High • Sai Praneeth R. Bathena • Santhi Gorantla • Larisa Y. Poluektova • \\ Yazen Alnouti • Howard E. Gendelman • Michael D. Boska
}

Received: 5 January 2013 / Accepted: 15 April 2013 / Published online: 24 May 2013

(C) The Author(s) 2013. This article is published with open access at Springerlink.com

\begin{abstract}
Metabolites are biomarkers for a broad range of central nervous system disorders serving as molecular drivers and byproducts of disease pathobiology. However, despite their importance, routine measures of brain tissue metabolomics are not readily available based on the requirements of rapid tissue preservation. They require preservation by microwave irradiation, rapid freezing or other methods designed to reduce post mortem metabolism. Our research on human immunodeficiency virus type one (HIV-1) infection has highlighted immediate needs to better link histology to neural metabolites. To this end, we investigated such needs in well-studied rodent models. First, the dynamics of brain metabolism during ex vivo tissue preparation was shown by proton magnetic resonance spectroscopy in normal mice. Second, tissue preservation methodologies were assessed using liquid chromatography tandem mass spectrometry and immunohistology to measure metabolites and
\end{abstract}

A. A. Epstein · P. Narayanasamy • P. K. Dash · S. Gorantla •

L. Y. Poluektova $\cdot$ H. E. Gendelman

Department of Pharmacology and Experimental Neuroscience,

College of Medicine, University of Nebraska Medical Center,

Omaha, NE 68198, USA

A. A. Epstein • M. D. Boska

Department of Radiology, College of Medicine, University

of Nebraska Medical Center, Omaha, NE 68198, USA

S. P. R. Bathena $\cdot$ Y. Alnouti

Department of Pharmaceutical Sciences, College of Pharmacy, University of Nebraska Medical Center, Omaha, NE 68198, USA

R. High

Department of Biostatistics, College of Public Health, University of Nebraska Medical Center, Omaha, NE 68198, USA

H. E. Gendelman $(\bowtie)$

Department of Pharmacology and Experimental Neuroscience, Nebraska Medical Center, 985880, Omaha, NE 68198-5880, USA e-mail: hegendel@unmc.edu neural antigens. Third, these methods were applied to two animal models. In the first, immunodeficient mice reconstituted with human peripheral blood lymphocytes then acutely infected with HIV-1. In the second, NOD scid IL2 receptor gamma chain knockout mice were humanized with CD34+ human hematopoietic stem cells and chronically infected with HIV-1. Replicate infected animals were treated with nanoformulated antiretroviral therapy (nanoART). Results from chronic infection showed that microgliosis was associated with increased myoinostitol, choline, phosphocholine concentrations and with decreased creatine concentrations. These changes were partially reversed with nanoART. Metabolite responses were contingent on the animal model. Taken together, these studies integrate brain metabolomics with histopathology towards uncovering putative biomarkers for neuroAIDS.

Keywords Focused beam microwave irradiation $\cdot$ Neural antigens · Human immunodeficiency virus type one . neuroAIDS $\cdot$ Antigen preservation $\cdot$ Magnetic resonance spectroscopy $\cdot$ Metabolomics

\section{Introduction}

Histopathologic assessments of neural integrity are commonly used to study neuropathogenesis following human immunodeficiency virus (HIV) infection. Both liquid chromatography tandem mass spectrometry (LC-MS/MS) analyses of metabolites, proteins applied to cerebrospinal fluids (CSF) (Bonneh-Barkay et al. 2008; Wikoff et al. 2008; Velazquez et al. 2009) and proton magnetic resonance spectroscopy ( ${ }^{1} \mathrm{H}$ MRS) tests have sought biomarkers for HIV-associated neurocognitive disorders (HAND) in humans (Lentz et al. 2011; Valcour et al. 2012) and in relevant animal models (Boska et al. 2004; 
Ratai et al. 2011; Dash et al. 2011). Nonetheless, such approaches have fallen short in providing diagnostic information for several reasons. First, LC-MS/MS analysis of CSF only indirectly reflects ongoing brain metabolic activity (Laspiur et al. 2007; Rozek et al. 2007; Angel et al. 2012). Second, while ${ }^{1} \mathrm{H}$ MRS is capable of visualizing regional brain metabolites, its sensitivity is limited (Choi et al. 2007; Holt et al. 2012). There is thus a need for precise investigations into relationships between metabolites and tissue pathologies. We posit that this can be realized by combining targeted LC-MS/MS and tissue immunohistochemistry with efforts that seek optimal metabolite preservation. Such an approach would be most useful when applied to appropriate model systems in HIV-affected brain subregions.

To these ends, we combined investigations of tissue immunohistology with metabolite profiling for the characterization of disease-related events in rodent models of HIV infection and HAND. Focused beam microwave irradiation (FBMI) and rapid tissue freezing techniques were validated for their abilities to preserve brain metabolites. FBMI heat distribution was optimized for murine brain irradiation through the use of phantoms infused with temperature sensitive dyes. Flash tissue freezing was cross-validated against FBMI. We next reasoned that yet another confounder could be the animal system itself and its abilities to reflect human disease. Taking this also into consideration, we used both an acute model of HIV-1 infection using immunodeficient mice reconstituted with human peripheral blood lymphocytes (PBL) (Koyanagi et al. 1997; Gorantla et al. 2010b) and NOD scid IL2 receptor gamma chain knockout humanized mice transplanted with $\mathrm{CD} 34+$ hematopoietic stem cells (HSC) then chronically infected (Gorantla et al. 2010a; Dash et al. 2011) to test the genesis of virus-induced brain disease. These models tested the effects of HIV-1 infection on brain immunopathology and metabolite levels. Both models supported HIV-1 infection and showed changes in brain metabolism with concomitant astro- and micro- gliosis associated pathologies. However, only CD34+ humanized animals demonstrated associations between time-dependent losses in CD4+ T lymphocytes, virus infection, metabolite concentrations and glial activation. Importantly, each of these parameters were affected by antiretroviral therapy and supporting a wealth of prior data gathered from our laboratories during past investigation (Dash et al. 2012; Roy et al. 2012). Taken together, these studies demonstrate important technical and methodological considerations needed in assessing metabolic biomarkers of HIV-associated neuropathology.

\section{Materials and methods}

Animals, human cell reconstitutions and HIV-1 infection

NOD scid IL2 receptor gamma chain knockout, NOD.Cg-

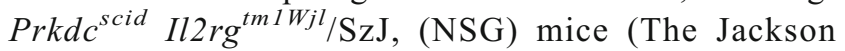

Laboratories, Bar Harbor, Maine, USA; stock number 005557) were obtained from an established breeding colony and housed under pathogen-free conditions in accordance with ethical guidelines for care of laboratory animals at the National Institutes of Health and the University of Nebraska Medical Center. All animal manipulations were performed in laminar flow hoods.

Human peripheral blood mononuclear cells (PBMC) were separated into a monocyte-and peripheral blood lymphocyte (PBL)-enriched fractions. PBL $\left(30 \times 10^{6}\right.$ cells in $0.5 \mathrm{ml}$ PBS $)$ were injected intraperitoneally (i.p.) into 4 week old NSG mice (hu-PBL) (Gorantla et al. 2010b). HIV-1 infection group were administered HIV-1 $1_{\mathrm{ADA}}$ (a CCR5 strain, (Gendelman et al. 1988)) i.p. at $10^{4} \times 50 \%$ tissue culture infective dose $\left(\mathrm{TCID}_{50}\right)$ on day 7 after PBL engraftment (hu-PBL-NSG HIV-1). Human pan-CD45, CD3, CD4, CD8, CD14 and CD19 markers were assayed as a six-color combination (BD Pharmingen, San Diego, California, USA) using a fluorescence-activated cell sorting (FACS) Diva (BD Immunocytometry Systems, Mountain View, California, USA) system. The percentages of $\mathrm{CD}^{+}$and $\mathrm{CD}^{+}$cells were obtained from the gate set on human $\mathrm{CD}^{+}$ cells. Blood collected in EDTA-containing tubes, for immune cell reconstitution profiles, were determined by FACS. All mice demonstrated hu-PBL reconstitution (Roy et al. 2012). Animals were sacrificed at 21 days after virus infection.

CD $34^{+}$HSCs were obtained from fetal liver (University of Washington, Laboratory of Developmental Biology supported by NIH Award Number 5R24HD000836) using magnetic beads $\mathrm{CD} 34^{+}$selection kit (Miltenyi Biotec Inc., Auburn, California, USA). Animals were transplanted as previously described (Gorantla et al. 2010a; Dash et al. 2011). Animals were infected with HIV-1 $1_{\mathrm{ADA}}$ i.p. at a dose of $10^{4} \mathrm{TCID}_{50}$ per mouse at 22 weeks following FACS validation of human immune cell reconstitution. Blood samples were collected at 2-week intervals during HIV infection in all animal groups to monitor human CD4/CD8 and viral load. The levels of viral RNA copies per $\mathrm{ml}$ in plasma were monitored by automated COBAS Amplicor System v1.5 (Roche Molecular Diagnostics, Basel, Switzerland). Animals were sacrificed at 18 weeks following HIV infection.

Nanoformulations using the excipient poloxamer-188 (P188; Sigma-Aldrich, St Louis, Missouri, USA), atazanavir (ATV)-sulfate (Gyma Laboratories of America Inc. Westbury, New York, USA) and free-base ritonavir (RTV) (Shengda Pharma-ceutical Co., Zhejiang, China) were prepared by high-pressure homogenization as described (Balkundi et al. 2010; Balkundi et al. 2011). Lyophilized nanoART particles were resuspended in saline and injected subcutaneous in HIV1-infected animals at 16 weekly doses of $250 \mathrm{mg} / \mathrm{kg}$ of ATV and RTV (Dash et al. 2012; Roy et al. 2012). NanoART was initiated following 12 weeks HIV infection.

Spleen and brain were collected after euthanasia and dissected over ice. Brains were initially split with left 
hemisphere for paraffin embedding and right hemisphere dissected into sub-regions for LC-MS/MS. Sub-regional dissection followed anatomical boundaries to separate hemi-brains into cerebellum, brainstem, cortex, hippocampus, striatum, and midbrain. Cortex was further divided into frontal and middle sections. Control NSG mice non-reconstituted with human cells and not HIVinfected serve for testing heat stabilization of brain tissue processing.

Agar-saline-thermochromic ink mouse (ASTIM) phantoms

A single 20-gram mouse was euthanized, coated in petroleum jelly and covered in plaster to make the primary mold (ArtPlaster ${ }^{\mathrm{TM}}$, Activa Products, Inc. Marshall, TX). After drying overnight the animal was removed from the mold and latex replicas were cast from the primary plaster mold (407 Latex Casting Rubber ${ }^{\circledR}$, EnvironMolds, Summit, NJ). These latex molds were used to make replicate agar phantoms of $2 \%$ agar in water with $0.9 \% \mathrm{NaCl}$ brought to boil. When molten agar cooled to $50^{\circ}$ concentrated thermochromic ink was added to a dilution of $5 \%$ (Chromax Black NH K60C, LCR Hallcrest, Glenview, IL). Phantoms were made by pouring molten agar mix into the latex molds and cooled over ice.

\section{FBMI euthansia and heat stabilization}

Mice were anesthetized by inhalation of $1-2 \%$ isoflurane in oxygen and aligned in water-jacketed animal holder for microwave irradiation in a Muromachi Microwave Fixation System (10 kW model). For phantom testing irradiation times from 400 to $700 \mathrm{~ms}$ were varied at $50 \mathrm{~ms}$ intervals at constant $4.9 \mathrm{~kW}$ for each buffer solution tested in the water jacket (distilled water, $0.5 \times, 1 \times, 2 \times, 3 \times, 4 \times$ PBS). Finally, these irradiation settings were tested on replicate animals followed by ${ }^{1} \mathrm{H}$ MRS validation.

\section{Quantitative ${ }^{1} \mathrm{H}$ MRS measurements}

Single voxel localized spectra were acquired using point resolved spectroscopy (PRESS) with high bandwidth pulses to optimize sequence performance. Spectra were acquired with a repetition time of $4 \mathrm{~s}$, echo time of $33 \mathrm{~ms}, 256$ averages, using volume coil transmit and surface coil receive on a $7 \mathrm{~T} / 16 \mathrm{~cm}$ Bruker Pharmascan (Karlsure, Germany) MRI/MRS system. Single-scan, localized, unsuppressed water signals were acquired as a reference for metabolite quantification. Spectroscopic data were processed by fitting in the time domain using the QUEST algorithm (Ratiney et al. 2005) with spectra (basis set) composed of GAMMA computer models of spectra (Smith et al. 1994) using published values of frequency and coupling constants from 22 abundant metabolites found in the brain by ${ }^{1} \mathrm{H}$ MRS (Govindaraju et al. 2000). These were normalized to water without correction for relaxation. Metabolite concentrations reported were semiquantitative. To preclude concentration corrections for relaxation, water normalized signal amplitudes were presented in institutional units (IU).

\section{LC-MS/MS analyses}

Nine Amino acids and myo-inositol (mInos) in mouse brain were quantified by LC-MS/MS conforming to previously published procedures (Bathena et al. 2012). The LC-MS/MS analyses were completed on a Waters ACQUITY ultraperformance liquid chromatography (UPLC) system (Waters, Milford, MA) coupled with a 4500 or 5500 Q TRAP $^{\circledR}$ hybrid quadrupole linear ion trap mass spectrometer (Applied Biosystems, MDS Sciex, Foster City, CA, no). Briefly, brain tissues were homogenized in methanol. Aliquots of homogenate were serially diluted with HPLC grade water, spiked with internal standard (IS) solution (Glu-d5), and extracted by protein precipitation using methanol. Samples were vortexed and centrifuged at $20,000 \mathrm{~g}$ for $10 \mathrm{~min}$. The supernatants were aspirated and evaporated under vacuum, the resulting residues were reconstituted in $50 \% \mathrm{ACN}$ and $10 \mu \mathrm{L}$ of 10,000 -fold diluted sample extracts were then subjected to LC-MS/MS analyses. The chromatographic separation was carried out with Atlantis ${ }^{\circledR}$ HILIC silica column $(150 \mathrm{~mm} \times 2.1 \mathrm{~mm}$ ID, $5 \mu \mathrm{m}$ particles $)$. Mobile phase A consisted of $0.1 \%$ formic acid in water and mobile phase B comprised of acetonitrile. The multiple reaction monitoring (MRM) transitions used for each analyte and IS were: glutamine (Gln) 147.0/129.9, mInos 178.9/160.9, gamma-aminobutyric acid (GABA) 104.0/68.9, glutamate (Glu) 148.0/84.0, N-acetylaspartate (NAA) 176.0/133.9, aspartate (Asp) 133.9/73.9, taurine (Tau) 125.9/107.8, choline (Cho) 104.0/60.0, creatine (Cre) 131.9/87.1, phosphocholine (PCho) 184.0/86.0, and Glu-d5 (IS) 153.0/88.0. Experiments performed on AB Sciex 5500 Q TRAP utilized the following optimized MRM transitions: mInos 178.8/117.1, GABA 104.0/86.9, Glu 146.1/101.9, NAA 173.9/87.9, Asp 132.0/88.1, Cho 104.1/60.0, and Cre 132.1/90.0.

Immunohistochemistry (IHC)

Brain hemispheres were extracted and then either post fixed overnight in $4 \%$ paraformaldehyde (PFA) before paraffin embedding or immediately processed through the alcohol/xylene dehydration steps in preparation for paraffin embedding. Sections $5 \mu \mathrm{m}$ thick were cut from paraffin blocks, mounted on glass slides and labeled separately with HLA-DQ/DP/DR, HIV-1 p24, glial fibrillary acidic protein (GFAP), and ionized calcium binding adaptor molecule 1 (Iba1) for brightfield 
imaging (Table 1). The polymer-based HRP-conjugated antimouse and anti-rabbit Dako EnVision systems were used as secondary detection reagents and developed with 3,3'diaminobenzidine (DAB). All paraffin-embedded sections were counterstained with Mayer's hematoxylin.

Adjacent slide specimens of paraffin-embedded mouse brain were selected for immunofluoresent staining. Brain sections were treated with primary mouse monoclonal antibodies to microtubule-associated protein 2 (MAP-2), vesicular glutamate transporter 1 (VGlut1), synapsin 1 (Snp1), neurofilament (NF), and vesicular GABA transporter (VGAT). Highly cross-adsorbed secondary anti-mouse, anti guinea pig and anti-rabbit antibodies conjugated to the fluorescent probes Alexa Fluor ${ }^{\circledR}$ 488, Alexa Fluor ${ }^{\circledR} 488$ and Alexa Fluor ${ }^{\circledR} 594$ respectively (Invitrogen, Carlsbad, CA) were used (Table 1). Cell nuclei were labeled with 4',6diamidino-2-phenylindole (DAPI). Slides were cover slipped with ProLong Gold anti-fade reagent (Invitrogen, Carlsbad, CA), allowed to dry for $24 \mathrm{~h}$ at room temp and then stored at $-20{ }^{\circ} \mathrm{C}$ for future use.

\section{Quantitative IHC}

Images were captured at multiple wavelengths (420$720 \mathrm{~nm}$ ) capturing the bandwidth of chromagens and the emission spectra of the fluorescent tags. All sections were imaged with $20 \times$ objective and synaptic-related stains were acquired using $40 \times$ objective. The spectra for each chromogen or fluorophore was determined on control slides and tissue sections were analyzed by multispectral imaging/image analysis, with a brightfield/fluorescence microscope (Nikon Eclipse 55i) and Nuance FX multispectral imaging system (Cambridge Research Instruments, Worburn, MA). A spectral un-mixing algorithm (Nuance system) quantitatively separated the grayscale images representing each spectral component. The grayscale images representing optical density (OD) for brightfield chromagen intensity or fluorescence signal counts per area $\left(\mathrm{mm}^{2}\right)$ (same exposure times for samples compared) was quantified as mean pixel intensity (12-bit grayscale). Area-weighted average intensity was calculated for all antibodies in triplicate for multiple regions in the brain (cortex, hippocampus, caudate, midbrain) by dividing the sum of the product of area and mean intensity, for each partitioned area, by the sum of the partitioned areas.

\section{Statistics}

Group metabolite data were examined for outliers or unequal variances. Group metabolite means were tested for significant differences using one-way univariate ANOVA with PROC MIXED of SAS. Significance of HIV infection and nanoART treatment variable was evaluated by F-tests; differences among pairs of means were then evaluated with T-Tests $(p \leq 0.05$ was assumed). If deemed necessary, an unequal variance ANOVA model was specified. Pairwise comparisons of means were computed and significance and confidence intervals for individual comparisons were adjusted for multiplicity with the Tukey method. All statistical significance tests were two-sided. Statistical analyses were generated with SAS/STAT software, Version 9.3 (C) 2002-2010) of the SAS System for Windows (Cary, NC).

Table 1 IHC Primary and Secondary Antibodies (Ab)

\begin{tabular}{|c|c|c|c|c|}
\hline Name & Target & $1^{\circ} \mathrm{Ab}$ & Company & $2^{\circ} \mathrm{Ab}$ \\
\hline HLA-DQ/DP/DR & human PBLs & $\begin{array}{l}\text { Mouse monoclonal } \\
\text { clone CR3/43, 1:100 }\end{array}$ & $\begin{array}{l}\text { DakoCytomation, } \\
\text { Carpinteria, CA }\end{array}$ & $\begin{array}{l}\text { HRP-conjugated anti- } \\
\text { mouse IgG }\end{array}$ \\
\hline HIV-1 p24 & HIV-1 core Ag & $\begin{array}{l}\text { Mouse monoclonal } \\
\text { clone Kal-1, 1:10 }\end{array}$ & $\begin{array}{l}\text { DakoCytomation, } \\
\text { Carpinteria, CA }\end{array}$ & $\begin{array}{l}\text { HRP-conjugated anti- } \\
\text { mouse IgG }\end{array}$ \\
\hline $\begin{array}{l}\text { Glial fibrillary acidic protein } \\
\text { (GFAP) }\end{array}$ & Astrocytes & $\begin{array}{l}\text { Rabbit polyclonal, } \\
1: 1000\end{array}$ & $\begin{array}{c}\text { DakoCytomation, } \\
\text { Carpinteria, CA }\end{array}$ & $\begin{array}{l}\text { HRP-conjugated anti- } \\
\text { rabbit IgG }\end{array}$ \\
\hline $\begin{array}{l}\text { Ionized calcium binding } \\
\text { adaptor molecule } 1 \text { (Iba1) }\end{array}$ & Microglia, macrophages & $\begin{array}{l}\text { Mouse monoclonal, } \\
1: 500\end{array}$ & $\begin{array}{l}\text { Wako Chemicals USA, } \\
\text { Inc., Richmond, VA }\end{array}$ & $\begin{array}{l}\text { HRP-conjugated anti- } \\
\text { mouse IgG }\end{array}$ \\
\hline $\begin{array}{l}\text { Microtubule-associated } \\
\text { protein } 2 \text { (MAP-2) }\end{array}$ & $\begin{array}{l}\text { Neuronal soma and } \\
\text { dendritic microtubulin }\end{array}$ & Rabbit polyclonal, 1:500 & $\begin{array}{l}\text { Millipore Corporation, } \\
\text { Temecula, CA }\end{array}$ & $\begin{array}{l}\text { Alexa Fluor }{ }^{\circledR} 594 \text { anti- } \\
\text { rabbit IgG }\end{array}$ \\
\hline $\begin{array}{l}200 \mathrm{kDa}+68 \mathrm{kDa} \\
\text { neurofilaments }(\mathrm{NF})\end{array}$ & $\begin{array}{l}\text { Neuronal axon } \\
\text { intermediate filaments }\end{array}$ & $\begin{array}{l}\text { Mouse monoclonal } \\
\text { clone } 2 \text { F11, 1:200 }\end{array}$ & $\begin{array}{l}\text { DakoCytomation, } \\
\text { Carpinteria, CA }\end{array}$ & $\begin{array}{l}\text { Alexa Fluor }{ }^{\circledR} 488 \text { anti- } \\
\text { mouse } \operatorname{IgG}\end{array}$ \\
\hline $\begin{array}{l}\text { Vesicular glutamate } \\
\text { transporter1 (VGlut1) }\end{array}$ & $\begin{array}{l}\text { Pre-synaptic excitatory } \\
\text { neurotranmission }\end{array}$ & $\begin{array}{l}\text { Guinnea Pig polyclonal, } \\
1: 1000\end{array}$ & $\begin{array}{l}\text { Synaptic Systems, } \\
\text { Göttingen, Germany }\end{array}$ & $\begin{array}{l}\text { Alexa Fluor }{ }^{\circledR} 488 \text { anti- } \\
\text { guinnea pig } \operatorname{IgG}\end{array}$ \\
\hline $\begin{array}{l}\text { Vesicular GABA transporter1 } \\
\text { (VGAT) }\end{array}$ & $\begin{array}{l}\text { Pre-synaptic inhibitory } \\
\text { neurotransmission }\end{array}$ & Rabbit polyclonal, 1:500 & $\begin{array}{l}\text { Synaptic Systems, } \\
\text { Göttingen, Germany }\end{array}$ & $\begin{array}{l}\text { Alexa Fluor }{ }^{\circledR} 594 \text { anti- } \\
\text { rabbit } \operatorname{IgG}\end{array}$ \\
\hline $\begin{array}{l}\text { synapsin } 1 \text { conjugated to } \\
\text { Oyster@ } 650(\mathrm{Snp} 1)\end{array}$ & Pre-synaptic marker & $\begin{array}{l}\text { Mouse monoclonal, } \\
1: 200\end{array}$ & $\begin{array}{l}\text { Synaptic Systems, } \\
\text { Göttingen, Germany }\end{array}$ & None \\
\hline
\end{tabular}




\section{Results}

FBMI for brain tissue preservation

Euthanasia by FBMI fixes brain tissue by heat inactivation of enzymes at temperatures above $65^{\circ} \mathrm{C}$ (Hampson et al. 1982). Achieving adequate heat is necessary to stabilize in vivo metabolite levels but excessive heating causes boiling in water compartments of tissues resulting in altered morphology or tissue destruction. To prevent such outcomes, we developed a heat distribution testing system for FBMI using mouse-shaped phantoms. Similar to systems designed to calibrate conventional microwaves for laboratory use (Login et al. 1998) we made agar molds shaped to the size of a $20 \mathrm{~g}$ mouse to produce phantoms modeling tissue using $2 \%$ agar and $0.9 \% \mathrm{NaCl}$ in water (Fig. 1c). Additionally, the phantom was loaded with thermo-sensitive dye that becomes permanently black at temperatures above $60^{\circ} \mathrm{C}$. Using this system we tested FBMI parameters for uniform heat distribution above $60{ }^{\circ} \mathrm{C}$ without reaching the melting point of agar at approximately $88^{\circ} \mathrm{C}$.
(Fig. 1d). The water-jacketed animal holder in the FBMI system provides a chamber around the head for buffer solution. The ionic concentration of buffer solution alters the field distribution and heat induction. Through phantom testing across a range of irradiation times we studied the effects of buffer ionic concentrations and irradiation time at a power setting of $4.9 \mathrm{~kW}$ without over-heating. To improve reproducibility and accommodate for differences in mouse size and fat distribution animal position within the irradiation chamber was further optimized using male and female adult NSG mice with ex vivo MRI and ${ }^{1} \mathrm{H}$ MRS validation. The optimal irradiation settings for this type and size of mice were: power $=4.9 \mathrm{~kW}$, time $=650 \mathrm{~ms}$ and buffer $=$ distilled water. For future experiments ASTIM phantoms were molded with $50 \mathrm{~mL}$ conical tubes and wrapped in latex for monitoring intra- and inter-day heat distribution reproducibility. Such variations are anticipated due to technical factors such as electrical power fluctuations and magnetron aging, which we detected and corrected at initiation of these experiments.

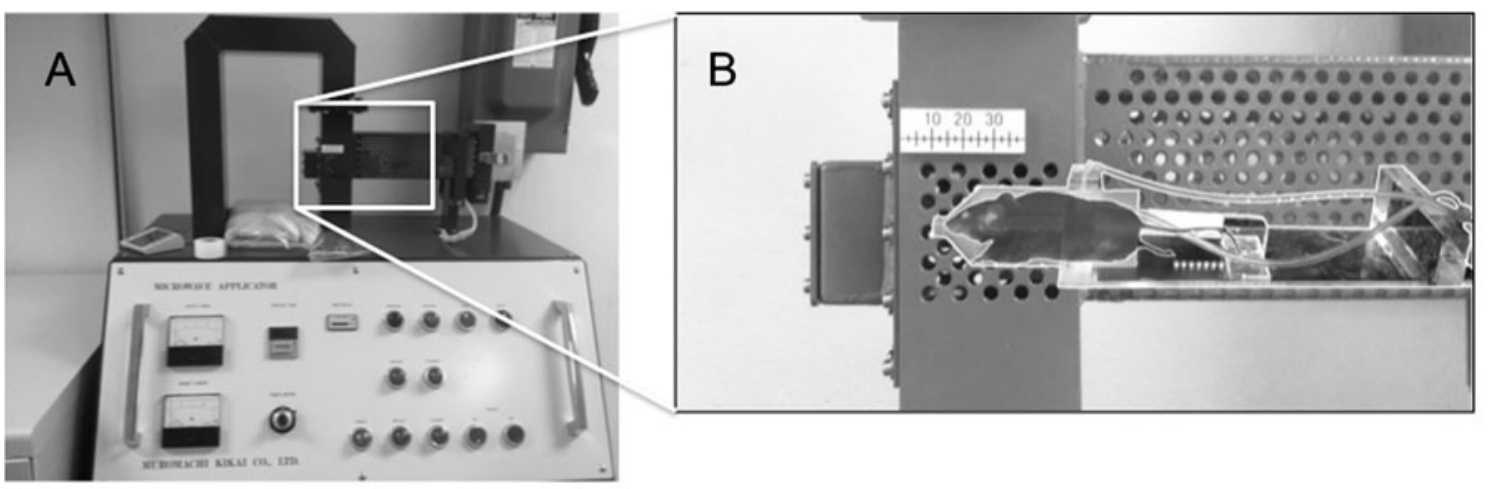

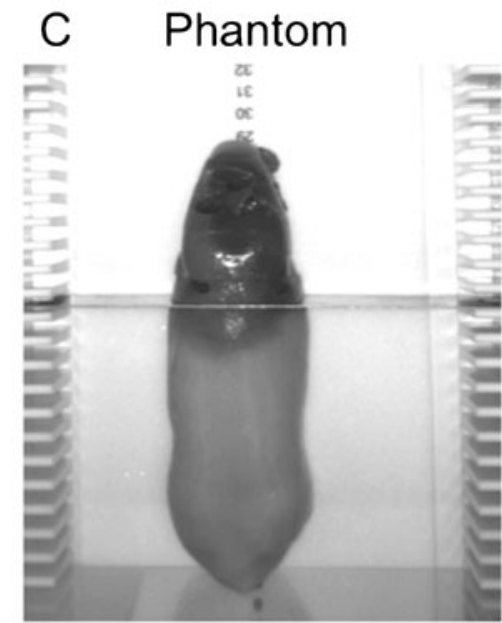

Fig. 1 FBMI euthanasia design and testing. (a) FBMI euthanasia was performed in a Muromachi $10 \mathrm{~kW}$ Microwave fixation system. (b) Mice are anesthetized and placed in an animal holder. The holder includes a water compartment filled with ionic buffer solution that aligns the mouse brain in the center of the waveguide. (c) An ASTIM

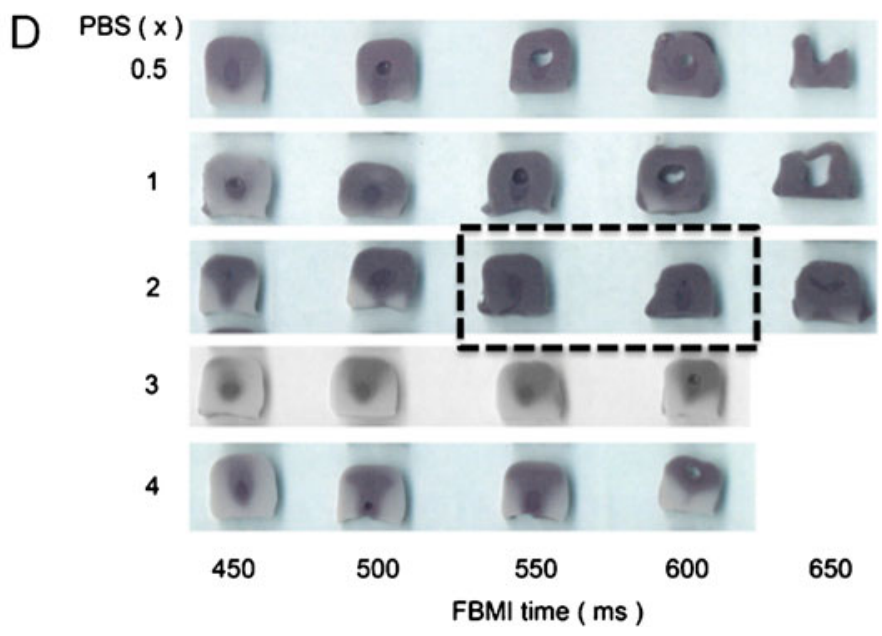

phantom was manufactured in order to develop standard operating microwave irradiation protocols that enable adequate heat distribution in the brain without boiling. (d) The ASTIM phantoms were used to test the effect of irradiation time and buffer solution for the rodents 


\section{FBMI and ${ }^{1} \mathrm{H}$ MRS}

Employing ${ }^{1} \mathrm{H}$ MRS allows the degree of metabolic stability to be determined by comparing post-mortem metabolite levels to those in live animals. Furthermore, the acquired metabolite profile provides confirmation of FBMI affects following previous works where ${ }^{1} \mathrm{H}-\mathrm{MRS}$ scanning of halothane-euthanized rat brain tissue compared to FBMI treatment demonstrated increased lactate, GABA, alanine and reduced NAA levels, representing residual enzymatic activities of energy respiration due to post mortem metabolism (de Graaf et al. 2009). Additionally, MRI also allows visualization of the tissue architecture, providing validation of the integrity of brain tissue after FBMI.

To characterize the effect of FBMI on mouse brain metabolites and to develop a method of assessing FBMI heating effectiveness, we collected a series of localized ${ }^{1} \mathrm{H}$ MRS spectra to generate a time course of metabolite levels. In vivo levels of brain metabolites followed by series of ex vivo scans over $16 \mathrm{~h}$ at room temperature in the same animal determined the capability of FBMI to maintain the integrity of in vivo metabolite levels through complete inactivation of enzymes (Fig. 2). Results are shown in retrospective groupings using lactate levels, one group representing insufficient heating (closed circles, $n=5$ ) and one with sufficient heating (open circles, $n=4$ ). The sufficient-heating group was defined as those with lactate levels matching in vivo levels after FBMI. Insufficient heating demonstrated a sharp 2fold increase in lactate in the first scan after FBMI. Lactate levels mirror NAA stabilization during the post-FBMI scanning period. Inadequate FBMI heating results in a sharp decrease in NAA. Lactate also correlated with increased GABA whereas no group differences were seen for Tau and Cre (data not shown). These data demonstrate the role of metabolite profiling to confirm tissue preservation where a single ex vivo scan session provides an assessment of heat stabilization to exclude samples where residual enzymatic activity remains active post mortem.

\section{LC-MS/MS measures of brain metabolites and preservation}

LC-MS/MS can be used to quantify brain metabolites including amino acids and mInos (Bathena et al. 2012). We performed targeted LC-MS/MS analysis to test the effect of tissue preservation in brain samples flash-frozen from mice sacrificed by decapitation compared to FBMI-treatment. Specific alterations in metabolite levels in the flash-frozen brains compared to FBMI-treatment were observed. Glu, GABA, mInos, and Cho significantly increased, whereas PCho decreased during flash-freezing relative to FBMItreatment (Fig. 3). In order to control for the possible effects of heating on tissue weight, concentrations were normalized to total protein. However, elimination of this normalization factor maintained the significant differences reported for all metabolites except Glu. Furthermore, contralateral samples from each brain were kept at room temperature for $60 \mathrm{~min}$
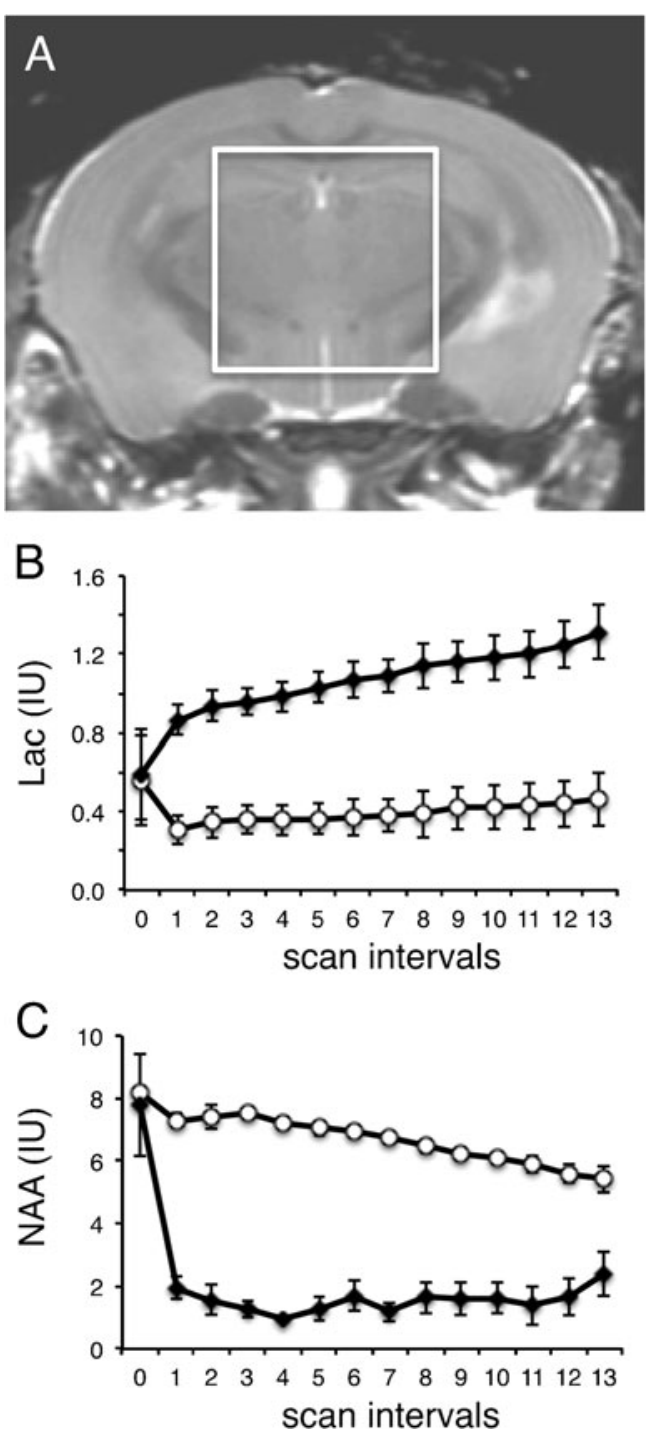

Fig. $2{ }^{1} \mathrm{H}$ MRS evaluations of brain metabolites. (a) Region of interest selected for single voxel ${ }^{1} \mathrm{H}$ MRS of the mouse brain in vivo and postmicrowave fixation. Results shown here demonstrate the effect of adequate and inadequate heat stabilization on metabolites determined retrospectively by comparing individual ex vivo to in vivo lactate levels (12 scans, $16 \mathrm{hs}$ ). (b) Lactate is stabilized with adequate heat (open circles, $n=4$ ) and does not change significantly over a 16 hour scan series, but levels double by the first scan interval (60 min) with inadequate heat. (c) Residual anaerobic respiration causes a sharp decrease in NAA levels by the first scan interval when adequate heat is not applied (closed circles, $n=5$ ). Metabolite concentrations are reported as institutional units (IU). Means at each timepoint are displayed with error bars indicating standard error of the mean

before freezing to evaluate individual sample stability. This assay provided 2 important results: (1) an FBMI-treated sample was excluded from the FBMI group due to inadequate stabilization following GABA increase and NAA decrease (data not shown); and (2) post-mortem metabolite dynamics (increased GABA and Cho with decreased PCho) due to residual metabolism in the flash frozen group were amplified during the processing delay (data not shown). 
Fig. 3 LC-MS/MS measured metabolites of heat stabilized brain tissues. (a) Metabolite levels measured with LC-MS/MS demonstrate increased Glu, GABA and Cho and reduced PCho when flash frozen (solid bars) relative to FBMI fixed tissue levels (open bars). Values shown are calculated as percentage of FBMI group mean. Error bars show standard error of the mean. *statistically significant group differences with $p<0.05$

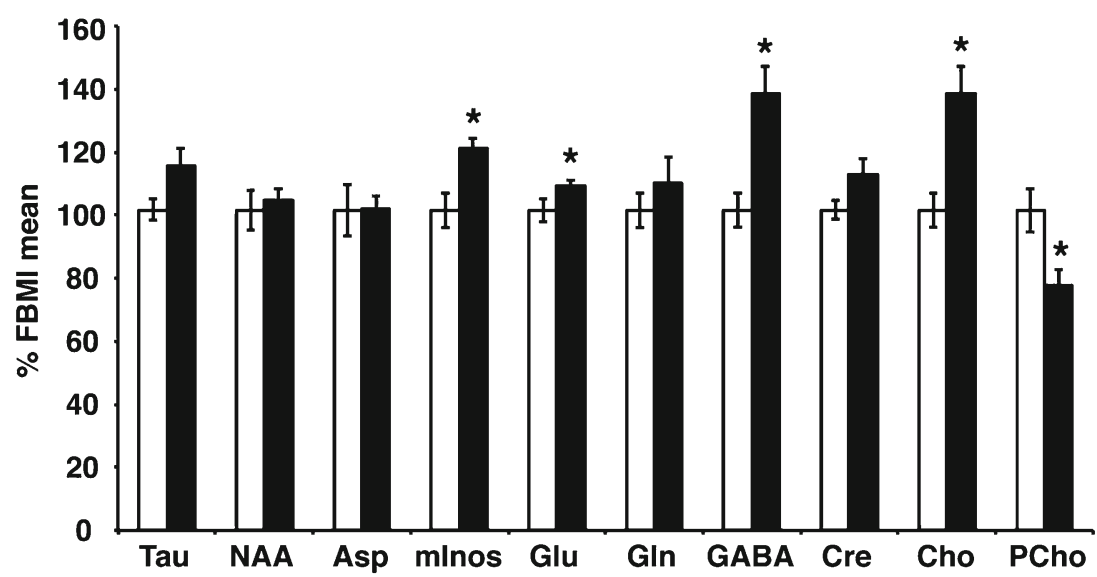

Concentrations of amino acids determined by LCMS/MS after FBMI of a duration of less than $1 \mathrm{~s}$ have been demonstrated to preserve metabolite concentrations of labile compounds in brain tissue (Delaney and Geiger 1996). In order to validate this in our studies, we have compared the results of the non-reconstituted NSG mice with values from in vivo quantitation of metabolite profiles in mouse brain from other laboratories (Table 2) (Schwarcz et al. 2003; Tkac et al. 2004). Considering the variability in normal concentrations in different mouse strains (Schwarcz et al. 2003), the concentrations are within range of literature values determined using non-invasive in vivo measures. Discrepancies between previous reports of brain metabolites measured by ${ }^{1} \mathrm{H}$ MRS and the LC-MS/MS results in our study are seen in Tau and Cre concentrations (Table 2). The reason for these discrepancies are not clear, however several causes may be responsible including the possibility that a percentage of these metabolites are bound to enzymes, proteins or membranes in vivo, decreasing ${ }^{1} \mathrm{H}$ MRS visibility due to line broadening.

Quantitative immunohistochemistry

Studies of neurodegenerative disease have relied on immunohistochemical techniques to identify morphological indicators of neuroinflammatory processes. The effect of FBMI on neural antigen preservation was investigated for markers of gliosis and neuronal integrity (Fig. 4). We compared quantitative immunohistochemistry (IHC) detection in typically prepared (decapitation followed by $4 \%$ PFA immersion overnight) brains to those processed with FBMI, with and without PFA immersion. Tissue histology and cellular morphology was

Table 2 Comparisons between brain metabolite concentrations from NSG mice with previously reported strains

\begin{tabular}{|c|c|c|c|c|}
\hline Metabolite & $\begin{array}{l}\text { LC-MS/MS } \\
\text { Concentration } \\
(\mathrm{mmol} / \mathrm{kg})\end{array}$ & $\begin{array}{l}\text { (Pfeuffer et al. } 1999) \\
\text { Concentration }(\mathrm{mmol} / \mathrm{kg}) \text { other } \\
\text { species }\end{array}$ & $\begin{array}{l}\text { (Tkac et al. 2004) concentration } \\
(\mathrm{mmol} / \mathrm{kg}) \text { regional variations }\end{array}$ & $\begin{array}{l}\text { (Schwarcz et al. 2003) } \\
\text { concentration }(\mathrm{mmol} / \mathrm{kg}) \\
\text { mice }\end{array}$ \\
\hline Aspartate & $2.3 \pm 0.4$ & $1.5-2.8$ & 2 & NR \\
\hline $\begin{array}{l}\text { Total Choline } \\
\text { (Cho+GPC+ } \\
\text { PCho) }\end{array}$ & $0.3 \pm 0.03$ (free Cho) & 0.5 & $1.5-2$ & $1.6-2.8$ \\
\hline $\begin{array}{l}\text { Creatine } \\
\text { (including } \\
\text { phosphoCre) }\end{array}$ & $14.9 \pm 2.0$ & $8-9$ & $8-13$ & $7.2-9.2$ \\
\hline $\begin{array}{l}\text { Gamma- } \\
\text { aminobutyric } \\
\text { acid }\end{array}$ & $2.9 \pm 0.7$ & $0.8-2.3$ & $2-3$ & NR \\
\hline Glutamate & $12.2 \pm 2.0$ & $7.5-12.5$ & $9-12.5$ & NR \\
\hline Glutamine & $3.7 \pm 0.7$ & $2.1-5.6$ & $3.5-4$ & NR \\
\hline myo-Inositol & $5.9 \pm 0.9$ & $4.4-10.5$ & $5-9$ & $5.2-6.6$ \\
\hline $\mathrm{N}$-acetylaspartate & $4.9 \pm 0.6$ & $6.0-7.1$ & $7-9$ & $6.5-7.9$ \\
\hline Phosphocholine & $0.5 \pm 0.06$ & 0.35 & (included in Cho) & (included in Cho) \\
\hline Taurine & $13.9 \pm 1.6$ & $1.6-6.6$ & $8-13$ & NR \\
\hline
\end{tabular}

$\mathrm{NR}=$ Not reported. Values in this report are means and standard deviations of values obtained from all brain regions from $n=4$ unmanipulated control NSG mice as seen in Fig. 4 

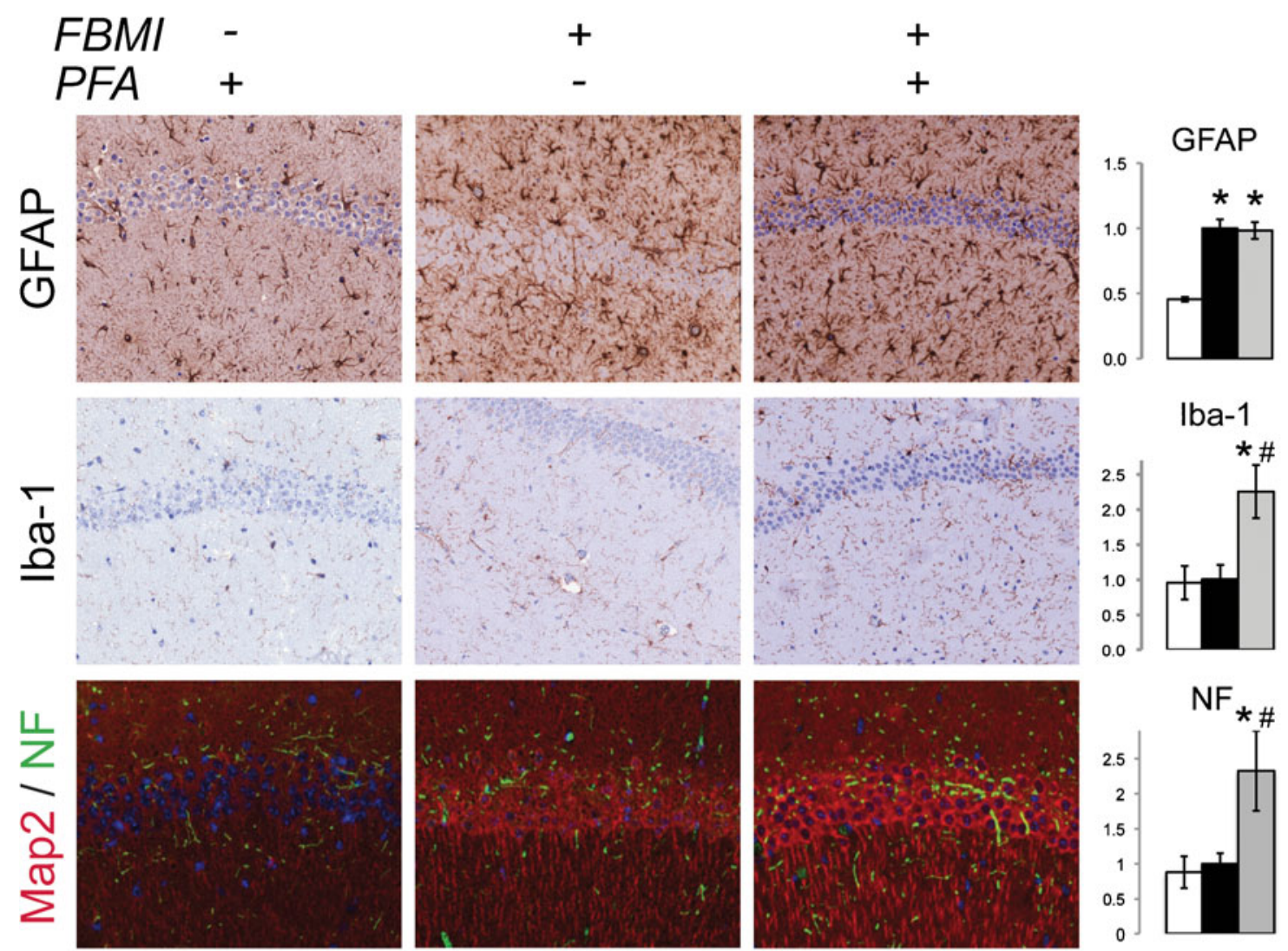

Iba-1
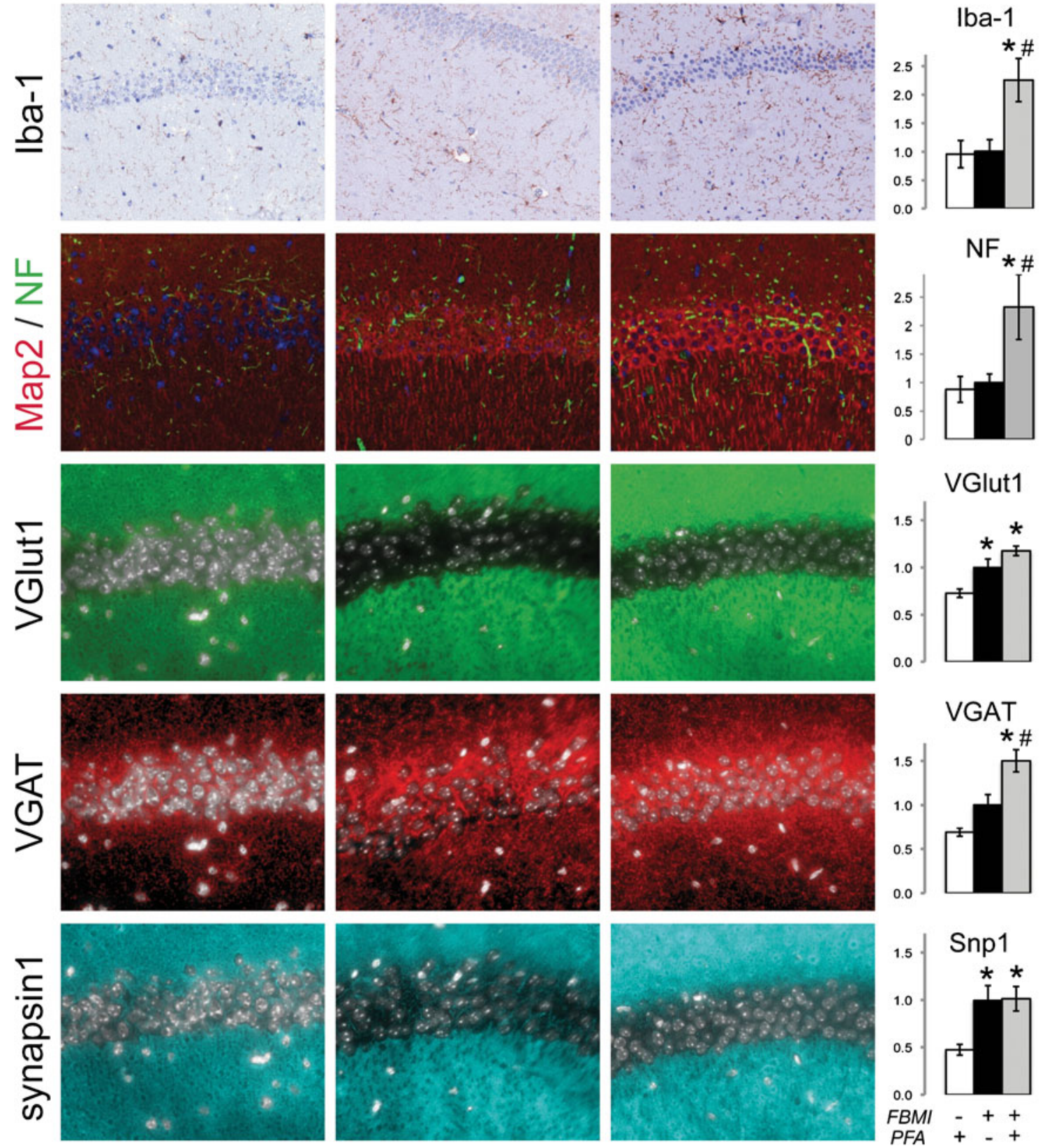

Fig. 4 Morphology of FBMI prepared brain tissue. Immunohistochemical analyses of astroglial (GFAP), microglial (Iba1), neuronal (MAP-2 and NF) and synaptic antigens (VGlut1, VGAT, and Snp1). These are readily observed in brain tissues recovered after FBMI and following with or without PFA fixation and paraffin embedding. GFAP, VGlut1 and Snp1 demonstrate increase signal with FBMI alone.
Antibodies against Ibal and synaptic antigens are preserved and enhanced with FBMI and PFA compared to no FBMI. FBMI reduces NF and nuclear staining with both hematoxylin and DAPI. *significant differences $(p<0.05)$ compared to non-FBMI. \# significant differences $(p<0.05)$ compared to FBMI alone 
intact in FBMI stabilized tissue. IHC detection demonstrated greater signal for brain tissue from FBMI euthanized animals over standard PFA preparation for GFAP, MAP-2, VGlut1 and Snp1 proteins (Fig. 4, Table 1). Analysis of the density of Iba1 and VGAT were increased for FBMI and PFA tissue preparation as compared to standard PFA preparation. NF signal increased with FBMI unlike previous reports of FBMI-induced ultrastructural damage studied by electron microscopy, as reviewed in (Login et al. 1998). Nonetheless, FBMI improved antigen detection levels over decapitation and therefore provides a method of brain tissue preservation that excludes the need for chemical fixation when warranted.

FBMI facilitates measures of neural antigens and metabolites in hu-PBL mice

FBMI euthanasia allows multiple investigations of brain tissue due to metabolic and protein stability at room temperature for prolonged periods, facilitating dissection. We hypothesized that FBMI followed by ex vivo ${ }^{1} \mathrm{H}$ MRS validation of lactate and NAA stability preceding combined metabolomics and histology applied in a murine systemic HIV-infection model (hu-PBL-NSG HIV-1) would demonstrate the relationship of metabolites with neuropathogenic events. Hu-PBL reconstituted mice as controls and mice infected with HIV for 3 weeks were euthanized with FBMI, ${ }^{1} \mathrm{H}$ MRS scanned and dissected with opposing hemispheres of the brain from each animal for IHC antigen detection and LC-MS/MS metabolite measurements. Though ${ }^{1} \mathrm{H}-\mathrm{MRS}$ measurements validated stabilization of Lac and NAA levels (data not shown), LC$\mathrm{MS} / \mathrm{MS}$ metabolite measurements of brain subregions did not yield any group differences for HIV infected animals compared to hu-PBL-NSG mice (Fig. 5). Indeed, IHC analysis for CD45+ human immune cells demonstrated profound variability in circulating numbers of human lymphocytes and brain infiltrations among brain regions and between animals. Accordingly, each animal, regardless of HIV infection status demonstrated variability in neuroimmune reactions as seen with IHC measurements of GFAP and Ibal levels (Fig. 6). These results were confounded by a number of experimental variables that included: (1) delayed freeze time following ${ }^{1} \mathrm{H}$ MRS scanning; (2) the variabilities of hu-PBL engraftments; (3) graft-versus-host disease; (4) levels of viral infection and neuroinflammation seen in brain subregions; (5) circulating HIV-1 viral load; (6) human donor cell variabilities; and (7) levels of neuroimmune reactions including micro- and astrogliosis.

Flash freezing preservation of neural antigens and metabolites in humanized HIV-1 infected mice

In response to the issues identified in the experiment using huPBL-NSG HIV-1 mouse model, combined with identified issues with the reproducibility of FBMI at that time (see
Results/FBMI for Brain Preservations), we constructed an experiment limiting confounding variables. HIV-1 infection of humanized mice (hu-CD34-NSG HIV-1) provides a model of chronic infection over many months with evidence of neuroinflammation and neuropathogenesis (Gorantla et al. 2010a; Dash et al. 2011). Humanized mice were maintained for 18 weeks following HIV-1 infection. Additionally, a group of HIV-1 infected humanized mice were treated for the final 6 weeks with nanoformulated antiretroviral therapy (nanoART). After decapitation opposing hemispheres from the same animals were processed for IHC analysis or dissected for LC-MS/MS analysis. The time from decapitation to flash freezing were minimized and controlled as to prevent variability of post mortem metabolism. Measurements of hippocampal metabolites showed significant changes consisting of increased mInos, Cho, PCho and decreased Cre (Fig. 7). Interestingly, nanoART reduction of viral load led to recovery of mInos near control levels. IHC analysis revealed similar group effects where microgliosis was present in the hippocampus of HIV infected mice and decreased with nanoART treatment and reductions of viral loads (Fig. 8).

\section{Discussion}

In the current report, we developed techniques to preclude brain enzymatic activities leading to preservation of both neural antigens and metabolites. Such findings, have notable value for studies of neural metabolism and to develop metabolic biomarkers of tissue injury and disease pathologies. Specifically, the metabolite profiles found in specific brain regions provide early predictive monitoring of HAND as well as to follow therapeutic interventions. As a diagnosis of HAND is currently made by the exclusion of other comorbid conditions of the CNS, these works are certainly timely and of clinical relevance (Valcour et al. 2011).

Quantitative LC-MS/MS evaluation of amino acids and mInos in brain tissues was made possible by both FBMItreatment and flash freezing tissue preservation techniques. This provides a metabolite signature comparable to ${ }^{1} \mathrm{H}$ MRS metabolite stability measurements (de Graaf et al. 2009) and validated by high resolution magic angle spinning NMR (Detour et al. 2011). Importantly, the targeted metabolite profiling assays performed show the role of tissue preservation dependent on processing techniques. Furthermore, comparisons between histochemical assessments of neuroinflammation and metabolite profiling provided confirmation of disease processes, yet specific correlations between IHC and LC-MS/MS data did not yield specific correlations (data not shown). Indeed, such findings indicate the sensitivity of metabolomic research to neuroinflammatory processes where cell processes are disrupted before structural alterations are evident. Moreover, the metabolite concentrations are representative of entire brain regions while 
Fig. 5 HIV-hu-PBL LC-MS/

MS metabolite analyses. FBMI was used in studies of HIV-1 infected human PBL reconstituted immune deficient mice. Metabolites were measured post mortem by LC$\mathrm{MS} / \mathrm{MS}$ in multiple subregions following ${ }^{1} \mathrm{H}$ MRS

confirmation of Lac and NAA stability. Individual dissected regions did not demonstrate group differences results in (a) cortex or (b) hippocampus in mice reconstituted with human lymphocytes (open bars, $n=4$ ) compared with HIV-1 infected hu-PBL mice (solid bars, $n=4$ ). Error bars indicate standard error of the mean
A

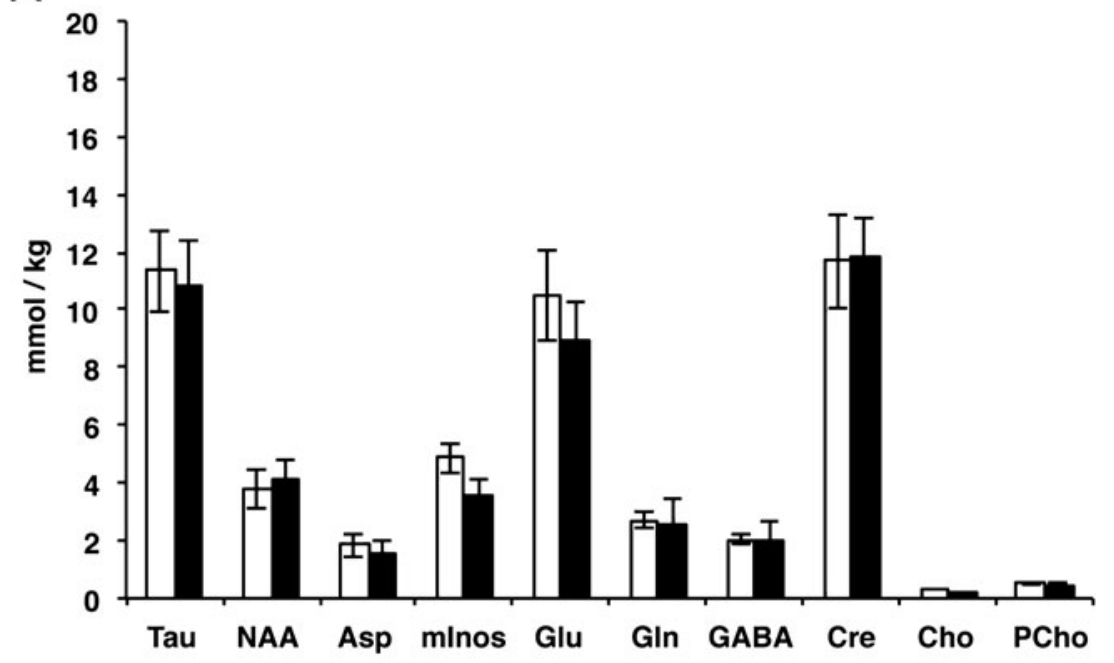

B

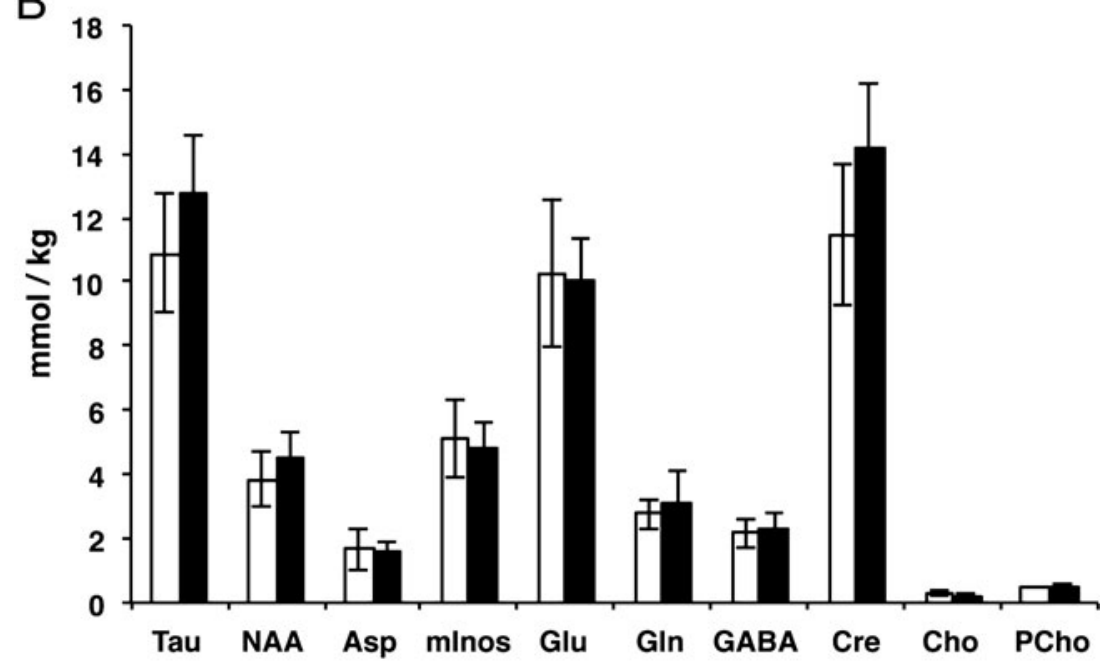

IHC is limited to individual slices. Future studies would explore other methods to link molecular biochemical processes during neuroinflammation utilizing methods such as in situ hybridization, laser capture microdissection and/or cytokine profiling for measurements of cell phenotype across many brain sections. Additionally, we anticipate that future studies will even better validate metabolite quantitation between these methodologies to refine the quantitative potential of ${ }^{1} \mathrm{H}$ MRS and provide even more exact measurements of a broad range of brain metabolites with post-mortem LC-MS/MS validation at the experimental endpoint in rodent models of disease.

FBMI was pursued as a lead technique to preserve brain metabolites as it has been proven effective in preventing the degradation of compounds after animal sacrifice. Indeed, studies linking behavior changes with energy metabolism and neurotransmitter deficits in animal models of Huntington Disease (Lucas et al. 2012; Mochel et al. 2012) and Alzheimer's (Francis et al. 2012) have relied on FBMI euthanasia to identify early disease events. Moreover, it has proven successful in stabilizing one of the most labile compounds in the brain, adenosine triphosphate (ATP). Indeed, efforts to obtain accurate ATP levels from brain tissue have led to the conclusion that ATP level stability can be seen in vivo only by high power $(10 \mathrm{~kW})$ FBMI and through freeze-blow procedures (Delaney and Geiger 1996). However the freezeblow technique, which involves blowing the brain tissue onto a very cold plate that prevents enzyme degradation, does not allow subsequent histological analyses. Apropos of the FBMI procedures and as performed in rats heated to $85{ }^{\circ} \mathrm{C}$, high power were believed needed to keep total heating time $\leq 1 \mathrm{~s}$ (Delaney and Geiger 1996). In the current study and as performed in mice, irradiation times of $0.6 \mathrm{~s}$ were below this threshold. Comparisons of the quantitative values obtained by LC-MS/MS showed that they were within the range of what was previously reported (Table 2).

What was clear is that metabolomic studies require attention to post mortem metabolism. Specifically, neural enzymatic activities seen as a consequence of hypoxic injury 


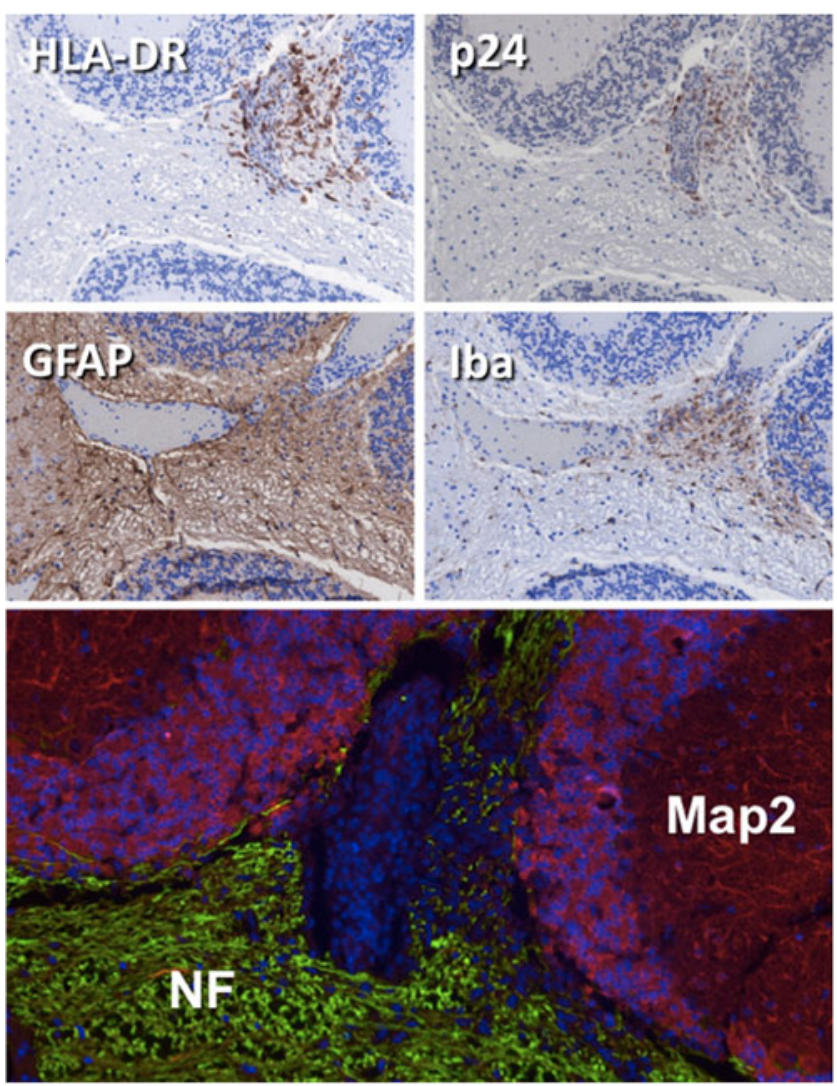

Fig. 6 Brain pathology in HIV-1 infected hu-PBL mice. Neuropathologic alterations in the cerebellum of an HIV-1 infected mouse. Human lymphocytes invade the parenchyma adjacent to blood vessel with p24 positive HIV-infected cells. GFAP and Iba1 staining shows inflammatory process in the vicinity. At this acute stage of inflammation gross neuronal morphology visualized by NF and MAP-2 remains intact

clearly affect metabolomics results. Studies using any disease animal model system must thus be evaluated for confounding effects due to tissue preparation (Nomura et al. 2011). Prior metabolomic studies while relying on rapid tissue preparations controlled for post mortem metabolism but did not report effects of tissue preparations (Cho et al. 2012; Fujieda et al. 2012; Patti et al. 2012). This study confirmed post-mortem metabolite dynamics and links between brain histology and metabolite profiles. This was done in relevant animal models of HIV-1 infection of the nervous system. Two model systems were used. In the first, HIV infection of hu-PBL-NSG mice was chosen for initial investigations. The model readily generates high levels of viral infection but is limited in the fact that mice survive for periods of several weeks due to lethal graft-versus-host disease. Even utilizing FBMI and ex vivo ${ }^{1} \mathrm{H}$ MRS we failed to show substantive group metabolomic differences. Indeed, histological analysis of these brains revealed significant variation in regional neuroimmune responses within reconstituted and in HIV infected animals. These variations may be explained by the differential severities of graft
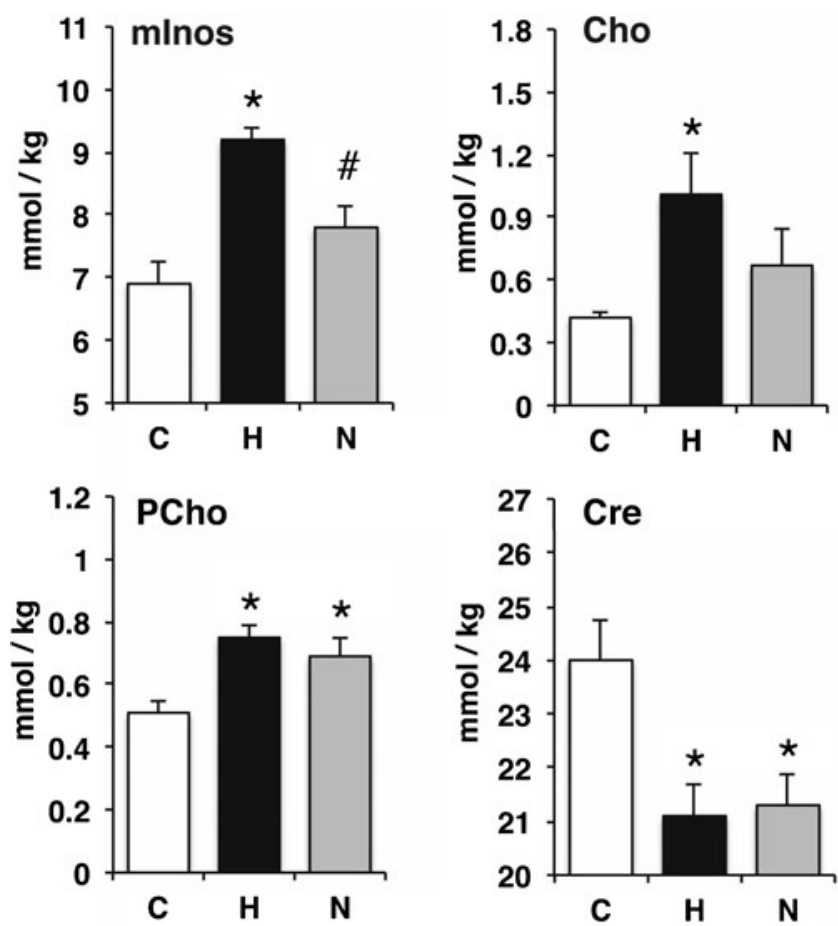

Fig. 7 LC-MS/MS metabolomic profiling of brain tissue from HIV-1 infected humanized mice. Metabolomic profiles were generated for flash frozen hippocampal tissues of humanized mice controls $(\mathrm{C}, n=$ 7), HIV-1 infection (H, $n=6)$ and HIV-1 infection treated with nanoART $(\mathrm{N}, n=6)$. Myo-Inositol (mInos), choline (Cho) and phosphorylcholine (PCho) increased and creatine (Cre) decreased during HIV-1 infection compared to humanized mice controls. NanoART reduction of HIV-1 disease reduced $\mathrm{mI}$ levels below the increase with HIV-1 infection. Error bars indicate standard deviation. * significant mean differences $(p<0.05)$ compared with uninfected humanized mouse brain controls, ${ }^{*}$ significant mean differences $(p<0.05)$ between HIV-1 infected and HIV-1 infected nanoART treated

versus host disease with human PBL reconstitution (King et al. 2009). While the model proved helpful for developing the techniques employed, we also realized that if any disease biomarker signature would be obtained from such metabolomics approaches a more robust animal model would need be developed and employed in study. This was found by HIV infection of humanized mice. In this model system human CD34+ cells are engrafted in newborn mice and reconstitute both innate and adaptive arms of the human immune system (Gorantla et al. 2012). Most importantly, humanized mice maintain human cell engraftment for over a year with minimal graft versus host disease. Furthermore, HIV infection leads to neuroimmune response (Gorantla et al. 2010a) and has been shown in our past works to provide a model system for developing new antiretroviral therapies (Dash et al. 2012; Nischang et al. 2012). Employing the model we were able to demonstrate, for the first time, CNS metabolite alterations in brain regions of infected mice. Specific metabolite changes following chronic (18 weeks) infection paralleled microglial profiles in the hippocampus 

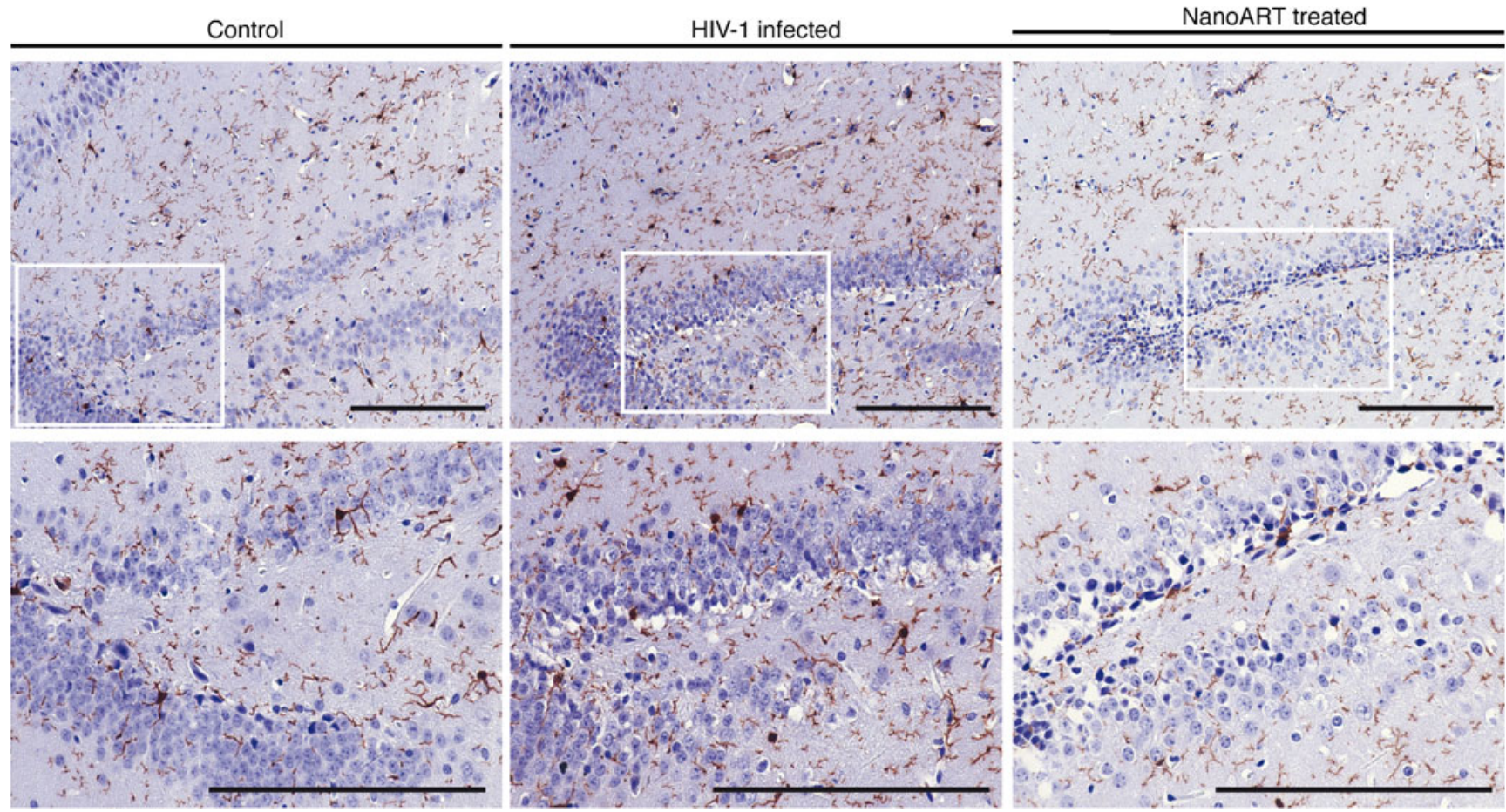

Fig. 8 Hippocampal microgliosis follows HIV-1 infection of humanized mice. Humanized NSG mice were infected with $\mathrm{HIV}-1_{\mathrm{ADA}}$ for 18 weeks. Brains were acquired after cervical decapitation and flash freezing. Following immunohistochemical stains of hippocampal brain slices numbers of Iba1 reactive cells were counted in the hippocampus in HIV-1 infected, HIV-1 infected and nanoART-treated and uninfected (controls). Photomicrographs of Iba1-stained sections are shown at $20 \times$ with $40 \times$ magnifications in areas of the dentate gyrus. (scale bar $=0.2 \mathrm{~mm}$ ) and were, in part, resolved by nanoART-induced suppression of viral loads (Fig. 7). Similar increases of mInos/Cre and $\mathrm{Cho} / \mathrm{Cre}$ were reported in brain subregions of HIV infected humans (Lentz et al. 2011) and SIV infected macaques (Greco et al. 2004). Additionally, hippocampal neuroinflammation was reported in rats peripherally administered IL-2 in an anxiety model showing concordance between myoinositol and microgliosis (Schneider et al. 2012).

We have shown that reductions of viral load readily observed by nanoART paralleled similar reductions of hippocampal microgliosis and myoinositol. However, the levels of Cho, PCho and Cre were reduced with HIV infection but did not return to baseline as was present for uninfected control animals. We suspect that such findings represent more permanent neurological damage seen as a consequence of the sustained high viral loads and acquired before treatment. This is also reflective of patients where initial neurocognitive deficits, although in part reversed by ART, can affect later cognitive function (Gendelman et al. 1998; Cysique et al. 2009). Additionally, the blood brain barrier limits ATV and RTV efficacy for the brain and the maintenance of the viral reservoir may limit neural recovery. This has previously been shown in studies comparing ART regimens according to a CNS penetrance index where neurocognitive recovery is linked to the drug regimen (Cysique et al. 2011). Though circulating levels of HIV
RNA are significantly reduced with 6 weekly injections of nanoART (Dash et al. 2012) other inflammatory factors may perpetuate the reactive phenotype of neural cells (KraftTerry et al. 2009; Yadav and Collman 2009). Finally, such limitations in metabolite recovery may reflect the hu-CD34NSG HIV-1 mouse model itself. Differences in donor human cells are one source of variability and levels of reconstitution are yet another. A third are immune effects seen by the genetic non-obese diabetic background, scid mutation, common cytokine gamma chain knockout, or within the chimeric immune system itself (Gong et al. 2011).

This study, in part, employed rapid flash freezing while controlling for tissue preparation dissection time. Future studies including FBMI euthanasia and profiling metabolite levels will be approached by targeted bioanalytical sample analyses reported here to validate sample preparation before untargeted metabolomic analyses (Maher et al. 2011; Zgoda-Pols et al. 2011) in conjunction with tissue morphological changes. Such studies will identify the biochemical neuroinflammatory pathways that influence synaptic dynamics. Moreover, such multidisciplinary studies including early and late time points of infection, behavioral studies and combinations of nanoART with neuroprotective adjuvants are certain to yield further insights into neuroimmune processes and the biochemical pathways mediating neurodegeneration. All together, the combinations of rapid 
tissue preparation for careful histological analyses that employ ${ }^{1} \mathrm{H}$ MRS and LC-MS/MS conjointly permit the acquisition of data not previously possible for biomarker discoveries. Such approaches also go a long way in substantiating the humanized mouse model system for studies of HIV neuropathogenesis as well as providing new predictive insights for disease.

Acknowledgements We thank Shantanu Balkundi for providing the nanoART materials and Edward Makarov, Jacklyn Knibbe, Tanuja Gutti, Sidra P Akhter, Melissa Mellon, Lindsay Rice, and Nagsen Gautam for technical assistance.

Open Access This article is distributed under the terms of the Creative Commons Attribution License which permits any use, distribution, and reproduction in any medium, provided the original author(s) and the source are credited.

\section{References}

Angel TE, Jacobs JM, Spudich SS, Gritsenko MA, Fuchs D, Liegler T, Zetterberg H, Camp DG 2nd, Price RW, Smith RD (2012) The cerebrospinal fluid proteome in HIV infection: change associated with disease severity. Clinical proteomics 9(1):3. doi:10.1186/ 1559-0275-9-3

Balkundi S, Nowacek AS, Roy U, Martinez-Skinner A, McMillan J, Gendelman HE (2010) Methods development for blood borne macrophage carriage of nanoformulated antiretroviral drugs. J Visual Exp (46). doi:10.3791/2460

Balkundi S, Nowacek AS, Veerubhotla RS, Chen H, Martinez-Skinner A, Roy U, Mosley RL, Kanmogne G, Liu X, Kabanov AV, Bronich T, McMillan J, Gendelman HE (2011) Comparative manufacture and cell-based delivery of antiretroviral nanoformulations. Int J Nanomedicine 6:3393-3404. doi:10.2147/IJN.S27830

Bathena SP, Huang J, Epstein AA, Gendelman HE, Boska MD, Alnouti Y (2012) Rapid and reliable quantitation of amino acids and myoinositol in mouse brain by high performance liquid chromatography and tandem mass spectrometry. J Chromatogr B Analyt Technol Biomed Life Sci 893-894:15-20. doi:10.1016/j.jchromb.2012.01.035

Bonneh-Barkay D, Bissel SJ, Wang G, Fish KN, Nicholl GC, Darko SW, Medina-Flores R, Murphey-Corb M, Rajakumar PA, Nyaundi J, Mellors JW, Bowser R, Wiley CA (2008) YKL-40, a marker of simian immunodeficiency virus encephalitis, modulates the biological activity of basic fibroblast growth factor. Am J Pathol 173(1):130-143. doi:10.2353/ajpath.2008.080045

Boska MD, Mosley RL, Nawab M, Nelson JA, Zelivyanskaya M, Poluektova L, Uberti M, Dou H, Lewis TB, Gendelman HE (2004) Advances in neuroimaging for HIV-1 associated neurological dysfunction: Clues to the diagnosis, pathogenesis and therapeutic monitoring. Curr HIV Res 2(1):61-78

Cho KI, Searle K, Webb M, Yi H, Ferreira PA (2012) Ranbp2 haploinsufficiency mediates distinct cellular and biochemical phenotypes in brain and retinal dopaminergic and glia cells elicited by the Parkinsonian neurotoxin, 1-methyl-4-phenyl-1,2,3,6tetrahydropyridine (MPTP). Cell Mol Life Sci 69(20):35113527. doi:10.1007/s00018-012-1071-9

Choi JK, Dedeoglu A, Jenkins BG (2007) Application of MRS to mouse models of neurodegenerative illness. NMR Biomed 20(3):216-237. doi:10.1002/nbm.1145

Cysique LA, Vaida F, Letendre S, Gibson S, Cherner M, Woods SP, McCutchan JA, Heaton RK, Ellis RJ (2009) Dynamics of cognitive change in impaired HIV-positive patients initiating antiretroviral therapy. Neurology 73(5):342-348. doi:10.1212/WNL.0b013e3181ab2b3b

Cysique LA, Waters EK, Brew BJ (2011) Central nervous system antiretroviral efficacy in HIV infection: A qualitative and quantitative review and implications for future research. BMC Neurol 11:148. doi:10.1186/1471-2377-11-148

Dash PK, Gendelman HE, Roy U, Balkundi S, Alnouti Y, Mosley RL, Gelbard HA, McMillan J, Gorantla S, Poluektova LY (2012) Long-acting nanoformulated antiretroviral therapy elicits potent antiretroviral and neuroprotective responses in HIV-1-infected humanized mice. AIDS 26(17):2135-2144. doi:10.1097/ QAD.0b013e328357f5ad

Dash PK, Gorantla S, Gendelman HE, Knibbe J, Casale GP, Makarov E, Epstein AA, Gelbard HA, Boska MD, Poluektova LY (2011) Loss of neuronal integrity during progressive HIV-1 infection of humanized mice. J Neurosci 31(9):3148-3157. doi:10.1523/ JNEUROSCI.5473-10.2011

de Graaf RA, Chowdhury GM, Brown PB, Rothman DL, Behar KL (2009) In situ 3D magnetic resonance metabolic imaging of microwave-irradiated rodent brain: A new tool for metabolomics research. J Neurochem 109(2):494-501. doi:10.1111/j.14714159.2009.05967.x

Delaney SM, Geiger JD (1996) Brain regional levels of adenosine and adenosine nucleotides in rats killed by high-energy focused microwave irradiation. J Neurosci Methods 64(2):151-156

Detour J, Elbayed K, Piotto M, Moussallieh FM, Nehlig A, Namer IJ (2011) Ultrafast in vivo microwave irradiation for enhanced metabolic stability of brain biopsy samples during HRMAS NMR analysis. J Neurosci Methods 201(1):89-97. doi:10.1016/ j.jneumeth.2011.07.014

Francis BM, Yang J, Hajderi E, Brown ME, Michalski B, McLaurin J, Fahnestock M, Mount HT (2012) Reduced tissue levels of noradrenaline are associated with behavioral phenotypes of the TgCRND8 mouse model of Alzheimer's disease. Neuropsychopharmacology : official publication of the American College of Neuropsychopharmacology 37(8):1934-1944. doi:10.1038/npp.2012.40

Fujieda Y, Ueno S, Ogino R, Kuroda M, Jonsson TJ, Guo L, Bamba T, Fukusaki E (2012) Metabolite profiles correlate closely with neurobehavioral function in experimental spinal cord injury in rats. PLoS One 7(8):e43152. doi:10.1371/journal.pone.0043152

Gendelman HE, Orenstein JM, Martin MA, Ferrua C, Mitra R, Phipps T, Wahl LA, Lane HC, Fauci AS, Burke DS et al (1988) Efficient isolation and propagation of human immunodeficiency virus on recombinant colony-stimulating factor 1-treated monocytes. J Exp Med 167(4):1428-1441

Gendelman HE, Zheng J, Coulter CL, Ghorpade A, Che M, Thylin M, Rubocki R, Persidsky Y, Hahn F, Reinhard J Jr, Swindells S (1998) Suppression of inflammatory neurotoxins by highly active antiretroviral therapy in human immunodeficiency virusassociated dementia. J Infect Dis 178(4):1000-1007

Gong N, Liu J, Reynolds AD, Gorantla S, Mosley RL, Gendelman HE (2011) Brain ingress of regulatory T cells in a murine model of HIV1 encephalitis. J Neuroimmunol 230(1-2):33-41. doi:10.1016/ j.jneuroim.2010.08.014

Gorantla S, Makarov E, Finke-Dwyer J, Castanedo A, Holguin A, Gebhart CL, Gendelman HE, Poluektova L (2010a) Links between progressive HIV-1 infection of humanized mice and viral neuropathogenesis. Am J Pathol 177(6):2938-2949. doi:10.2353/ ajpath.2010.100536

Gorantla S, Makarov E, Roy D, Finke-Dwyer J, Murrin LC, Gendelman HE, Poluektova L (2010b) Immunoregulation of a CB2 receptor agonist in a murine model of neuroAIDS. Journal of neuroimmune pharmacology: The official journal of the Society on NeuroImmune Pharmacology 5(3):456-468. doi:10.1007/ s11481-010-9225-8 
Gorantla S, Poluektova L, Gendelman HE (2012) Rodent models for HIV-associated neurocognitive disorders. Trends Neurosci 35(3):197-208. doi:10.1016/j.tins.2011.12.006

Govindaraju V, Young K, Maudsley AA (2000) Proton NMR chemical shifts and coupling constants for brain metabolites. NMR Biomed 13(3):129-153

Greco JB, Westmoreland SV, Ratai EM, Lentz MR, Sakaie K, He J, Sehgal PK, Masliah E, Lackner AA, Gonzalez RG (2004) In vivo $1 \mathrm{H}$ MRS of brain injury and repair during acute SIV infection in the macaque model of neuroAIDS. Magnetic resonance in medicine: Official journal of the Society of Magnetic Resonance in Medicine/Society of Magnetic Resonance in Medicine 51(6):1108-1114. doi:10.1002/mrm.20073

Hampson RK, Medina MA, Olson MS (1982) The use of high-energy microwave irradiation to inactivate mitochondrial enzymes. Anal Biochem 123(1):49-54

Holt JL, Kraft-Terry SD, Chang L (2012) Neuroimaging studies of the aging HIV-1-infected brain. Journal of neurovirology 18(4):291302. doi:10.1007/s13365-012-0114-1

King MA, Covassin L, Brehm MA, Racki W, Pearson T, Leif J, Laning J, Fodor W, Foreman O, Burzenski L, Chase TH, Gott B, Rossini AA, Bortell R, Shultz LD, Greiner DL (2009) Human peripheral blood leucocyte non-obese diabetic-severe combined immunodeficiency interleukin-2 receptor gamma chain gene mouse model of xenogeneic graft-versus-host-like disease and the role of host major histocompatibility complex. Clin Exp Immunol 157(1):104-118. doi:10.1111/j.1365-2249.2009.03933.x

Koyanagi Y, Tanaka Y, Kira J, Ito M, Hioki K, Misawa N, Kawano Y, Yamasaki K, Tanaka R, Suzuki Y, Ueyama Y, Terada E, Tanaka T, Miyasaka M, Kobayashi T, Kumazawa Y, Yamamoto N (1997) Primary human immunodeficiency virus type 1 viremia and central nervous system invasion in a novel hu-PBL-immunodeficient mouse strain. J Virol 71(3):2417-2424

Kraft-Terry SD, Buch SJ, Fox HS, Gendelman HE (2009) A coat of many colors: neuroimmune crosstalk in human immunodeficiency virus infection. Neuron 64(1):133-145. doi:10.1016/ j.neuron.2009.09.042

Laspiur JP, Anderson ER, Ciborowski P, Wojna V, Rozek W, Duan F, Mayo R, Rodriguez E, Plaud-Valentin M, Rodriguez-Orengo J, Gendelman HE, Melendez LM (2007) CSF proteomic fingerprints for HIV-associated cognitive impairment. J Neuroimmunol 192(1-2):157-170. doi:10.1016/j.jneuroim.2007.08.004

Lentz MR, Kim WK, Kim H, Soulas C, Lee V, Venna N, Halpern EF, Rosenberg ES, Williams K, Gonzalez RG (2011) Alterations in brain metabolism during the first year of HIV infection. Journal of neurovirology 17(3):220-229. doi:10.1007/s13365-011-0030-9

Login GR, Leonard JB, Dvorak AM (1998) Calibration and standardization of microwave ovens for fixation of brain and peripheral nerve tissue. Methods 15(2):107-117. doi:10.1006/meth.1998.0613

Lucas EK, Dougherty SE, McMeekin LJ, Trinh AT, Reid CS, Cowell RM (2012) Developmental alterations in motor coordination and medium spiny neuron markers in mice lacking pgc-1alpha. PLoS One 7(8):e42878. doi:10.1371/journal.pone.0042878

Maher AD, Cysique LA, Brew BJ, Rae CD (2011) Statistical integration of $1 \mathrm{H}$ NMR and MRS data from different biofluids and tissues enhances recovery of biological information from individuals with HIV-1 infection. Journal of proteome research 10(4):1737-1745. doi:10.1021/pr1010263

Mochel F, Durant B, Meng X, O'Callaghan J, Yu H, Brouillet E, Wheeler VC, Humbert S, Schiffmann R, Durr A (2012) Early alterations of brain cellular energy homeostasis in Huntington disease models. J Biol Chem 287(2):1361-1370. doi:10.1074/ jbc.M111.309849

Nischang M, Sutmuller R, Gers-Huber G, Audige A, Li D, Rochat MA, Baenziger S, Hofer U, Schlaepfer E, Regenass S, Amssoms K, Stoops B, Van Cauwenberge A, Boden D, Kraus G, Speck RF
(2012) Humanized mice recapitulate key features of HIV-1 infection: a novel concept using long-acting anti-retroviral drugs for treating HIV-1. PLoS One 7(6):e38853. doi:10.1371/ journal.pone. 0038853

Nomura DK, Morrison BE, Blankman JL, Long JZ, Kinsey SG, Marcondes MC, Ward AM, Hahn YK, Lichtman AH, Conti B, Cravatt BF (2011) Endocannabinoid hydrolysis generates brain prostaglandins that promote neuroinflammation. Science 334(6057):809-813. doi:10.1126/science.1209200

Patti GJ, Yanes O, Shriver LP, Courade JP, Tautenhahn R, Manchester M, Siuzdak G (2012) Metabolomics implicates altered sphingolipids in chronic pain of neuropathic origin. Nat Chem Biol 8(3):232-234. doi:10.1038/nchembio.767

Pfeuffer J, Tkac I, Provencher SW, Gruetter R (1999) Toward an in vivo neurochemical profile: quantification of 18 metabolites in short-echo-time (1)H NMR spectra of the rat brain. J Magn Reson 141(1):104-120. doi:10.1006/jmre.1999.1895

Ratai EM, Annamalai L, Burdo T, Joo CG, Bombardier JP, Fell R, Hakimelahi R, He J, Lentz MR, Campbell J, Curran E, Halpern EF, Masliah E, Westmoreland SV, Williams KC, Gonzalez RG (2011) Brain creatine elevation and N-Acetylaspartate reduction indicates neuronal dysfunction in the setting of enhanced glial energy metabolism in a macaque model of neuroAIDS. Magnetic resonance in medicine: Official journal of the Society of Magnetic Resonance in Medicine/Society of Magnetic Resonance in Medicine 66(3):625-634. doi:10.1002/mrm.22821

Ratiney H, Sdika M, Coenradie Y, Cavassila S, van Ormondt D, Graveron-Demilly D (2005) Time-domain semi-parametric estimation based on a metabolite basis set. NMR Biomed 18(1):1-13. doi: $10.1002 / \mathrm{nbm} .895$

Roy U, McMillan J, Alnouti Y, Gautum N, Smith N, Balkundi S, Dash P, Gorantla S, Martinez-Skinner A, Meza J, Kanmogne G, Swindells S, Cohen SM, Mosley RL, Poluektova L, Gendelman HE (2012) Pharmacodynamic and antiretroviral activities of combination nanoformulated antiretrovirals in HIV-1-infected human peripheral blood lymphocyte-reconstituted mice. J Infect Dis 206(10):1577-1588. doi:10.1093/infdis/jis395

Rozek W, Ricardo-Dukelow M, Holloway S, Gendelman HE, Wojna V, Melendez LM, Ciborowski P (2007) Cerebrospinal fluid proteomic profiling of HIV-1-infected patients with cognitive impairment. J Prot Res 6(11):4189-4199. doi:10.1021/pr070220c

Schneider P, Weber-Fahr W, Schweinfurth N, Ho YJ, Sartorius A, Spanagel R, Pawlak CR (2012) Central metabolite changes and activation of microglia after peripheral interleukin-2 challenge. Brain Behav Immun 26(2):277-283. doi:10.1016/ j.bbi.2011.09.011

Schwarcz A, Natt O, Watanabe T, Boretius S, Frahm J, Michaelis T (2003) Localized proton MRS of cerebral metabolite profiles in different mouse strains. Magnetic resonance in medicine: Official journal of the Society of Magnetic Resonance in Medicine/ Society of Magnetic Resonance in Medicine 49(5):822-827. doi:10.1002/mrm.10445

Smith SA, Levante TO, Meier BH, Ernst RR (1994) Computer Simulations in Magnetic Resonance. An Object-Oriented Programming Approach. J Magnet Reson, Series A 106(1):75105. doi:10.1006/jmra.1994.1008

Tkac I, Henry PG, Andersen P, Keene CD, Low WC, Gruetter R (2004) Highly resolved in vivo 1H NMR spectroscopy of the mouse brain at $9.4 \mathrm{~T}$. Magnetic resonance in medicine: Official journal of the Society of Magnetic Resonance in Medicine/ Society of Magnetic Resonance in Medicine 52(3):478-484. doi:10.1002/mrm.20184

Valcour V, Chalermchai T, Sailasuta N, Marovich M, Lerdlum S, Suttichom D, Suwanwela NC, Jagodzinski L, Michael N, Spudich S, van Griensven F, de Souza M, Kim J, Ananworanich J (2012) Central nervous system viral invasion and inflammation 
during acute HIV infection. J Infect Dis 206(2):275-282. doi:10.1093/infdis/jis326

Valcour V, Paul R, Chiao S, Wendelken LA, Miller B (2011) Screening for cognitive impairment in human immunodeficiency virus. Clinical infectious diseases: An official publication of the Infectious Diseases Society of America 53(8):836-842. doi:10.1093/cid/cir524

Velazquez I, Plaud M, Wojna V, Skolasky R, Laspiur JP, Melendez LM (2009) Antioxidant enzyme dysfunction in monocytes and CSF of Hispanic women with HIV-associated cognitive impairment. J Neuroimmunol 206(1-2):106-111. doi:10.1016/ j.jneuroim.2008.10.013

Wikoff WR, Pendyala G, Siuzdak G, Fox HS (2008) Metabolomic analysis of the cerebrospinal fluid reveals changes in phospholipase expression in the CNS of SIV-infected macaques. J Clin Invest 118(7):2661-2669. doi:10.1172/JCI34138

Yadav A, Collman RG (2009) CNS inflammation and macrophage/ microglial biology associated with HIV-1 infection. Journal of neuroimmune pharmacology: The official journal of the Society on NeuroImmune Pharmacology 4(4):430-447. doi:10.1007/ s11481-009-9174-2

Zgoda-Pols JR, Chowdhury S, Wirth M, Milburn MV, Alexander DC, Alton KB (2011) Metabolomics analysis reveals elevation of 3indoxyl sulfate in plasma and brain during chemically-induced acute kidney injury in mice: Investigation of nicotinic acid receptor agonists. Toxicol Appl Pharmacol 255(1):48-56. doi:10.1016/ j.taap.2011.05.015 